\title{
PREVALENCE AND ASSOCIATED RISK FACTORS OF CYSTICECHINOCOCCOSIS IN PIGS SLAUGHTERED AT ADDIS ABABA ABATTOIR ENTERPRISE
}

\author{
Abraham AYELE, Elias GEZAW and Mastewal BIRHAN \\ College of Veterinary Medicine and Animal science, Department veterinary Paraclinical studies, University of Gondar, Gondar, Ethiopia \\ Email: maste65@gmail.com; ORCID: 0000-0002-0984-5582 \\ supporting Information
}

ABSTRACT: A cross sectional study was conducted from January 2018 to April 2018 to determine the prevalence and associated risk factors of cystic echinococcosis in pig slaughtered at Addis Ababa abattoir enterprise, central part of Ethiopia. A total of $\mathbf{2 5 1}$ pigs were randomly sampled and routine meat inspection procedure was employed to detect the presence of hydatid cyst in the visceral organs (lung, liver, spleen and kidney), where 25 (9.96\%) pigs were positive. Analysis of risk factors for occurrence of the disease revealed that there was statistically significant variation $(P<0.05)$ in swine with different body condition scores and age groups. However, significant variation was not observed $(P>0.05)$ across different sex and origin. Prevalence of distribution of hydatid cyst in different organs from total examined swine were $3.59 \%, 3.19 \%, 1.99 \%, 0.80 \%, 0.40 \%$, for lungs and livers, livers, lungs, spleens and kidney respectively. In this study, the liver was found to be the most predominantly affected organ $(6.77 \%)$ followed by the lungs $(5.58 \%)$, spleen $(0.80 \%)$ and the least affected organ was kidney $(0.40 \%)$. As regards size of the cyst from total infected organs, organ with small sized cysts had the highest percentage $(67.6 \%)$, followed by medium sized cysts $(20.6 \%)$ and large sized cysts $(11.8 \%)$. Livers $(44.1 \%)$ were predominant organ infected with small cyst size while spleen $(5.9 \%)$ and kidney $(2.9 \%)$ have only small cyst size. Lungs $(14.7 \%)$ and liver $(5.9 \%)$ were infected with medium cyst size while only lungs $(11.8 \%)$ have large cyst size. From the total of $34(100 \%)$ affected organs, only $4(11.8 \%)$ lungs have more than or equal to three cyst numbers while remaining $30(88.2 \%)$ affected organs were with less than three cyst numbers.

Keywords: Cyst number, Cyst size, Echinococcosis, Echinococcus granulosus, Hydatid cysts, Prevalence, Risk factors.

\section{INTRODUCTION}

Pigs, also called as hogs or swine, are ungulates which have been domesticated as a source of food, leather and similar products since ancient times. More in recent times, they have been involved in biochemical research and treatment (Pam et al., 2013). Swine production forms a fundamental part of farmer's economy in many parts of the world. Many countries practice different kinds of production approaches. Swine production is increasing from time to time in many parts of tropical countries. An increased demand on international market, due to increased number of pork consumer and the profit obtained from the sector make the production to increase rapidly (Serres, 2001). However, pig production in developing countries is contributing little benefits due to many production constraints including; under developed infrastructure, poor genetic performance of local breeds, insufficient nutrition, poor management and husbandry practices, shortage of trained man power, cultural and religious taboo on marketing and consumption of pork and wide spread diseases (FAO, 2000).

Pig production in Ethiopia is to be in its newborn stage until current day. The pig population in the country is estimated to be 29,000 heads representing $0.1 \%$ of African pig population (FAO, 2005). In many rural parts of Ethiopia, pig production was characterized by extensive production system whereby animals are allowed to forage at backyard and municipal debris discarding sites (Abdu and Gashaw, 2010). On the other hand, extensive husbandry system coupled with poor environmental hygiene and voracious feeding behavior of pigs have been indicated as a major risk factor for infection of pigs with helminthes and gastrointestinal parasites where pigs may act as potential reservoir hosts of human gastro-intestinal parasites such as ascaris (Irvin, 2003).

Cystic echinococcosis (CE) is one of the most important helminthes zoonosis and rests as a major problem worldwide. It is caused by the larval stages of the tapeworm Echinococcus granulose, which is found in the small intestines of dogs and other carnivores. It is also is known to be one of the most important parasitic infections in livestock worldwide (Craig et al., 2007). In Ethiopia, hydatidosis (Cystic echinococcosis in pig) is one of the major parasitic zoonotic diseases particularly where pigs, shoat, cattle and camel are still slaughtered traditionally and offal's are effortlessly accessible to scavenging dog and other wild carnivores. Factors like absence of proper meat inspection procedure, poor supervision of food animals, traditional practices of back yard farming system, lack of attentiveness about food borne 
disease and presence of large stray dog population contribute significantly to the prevalence of the disease in Ethiopia (Yetinayet, 2010).

The parasite has an indirect life cycle utilizing dogs and other canids as definitive hosts and many herbivorous and omnivorous species, including wildlife and domesticated livestock as intermediate hosts. The tapeworm spends most of its adult life in the intestine of its definitive host, namely canids in particular dogs. The tapeworm eggs become voided in the canids' faeces and as a result of ingesting the eggs, infection passes to the intermediate host, commonly herbivores while grazing. However, humans can become accidentally infected and hydatid cysts may develop throughout the body (Ahmadi and Meshkehkar, 2011). As it is indicated in numerous medical literatures, hydatidosis is also a well-recognized zoonosis (Ali et al., 2008). In each year due to hydatidosis, a significant amount of economic loss results from death of animals, inferior weight gain, condemnation of edible organs and carcass at slaughter houses. This production loss to the livestock industry is expected to be more than 900 million USD annually (Andualem, 2007).

Factors governing the prevalence of hydatidosis in a given district may be associated with prevailing specific social, cultural, environmental and epidemiological conditions. It has a considerable socio-economic effect in countries where livestock industry is an important segment of agricultural sector and when livestock production is based mainly on extensive grazing system (Berhe, 2009). Similarly its significance is higher in developing countries particularly in rural communities where there is a close contact between dogs (definitive host) and various domestic animals which are intermediate host (Eckert and Deplazes, 2004; Eckert et al., 2001). Echinococcus granulosus, a causative agent of hydatidosis, is wide spread in Ethiopia with great economic and public health significance (Sisay et al., 2008; Nigatu et al., 2009). In spite of the large efforts that have been put into the research and control of echinococcosis, it still remains a disease of worldwide significance. In some areas of the world, Cystic echinococcosis caused by E. granulosus is a reemerging disease in places where it was previously at low levels (Torgerson and Budke, 2003).

The general objective of the study was to know the current prevalence and associated risk factors of cystic echinococcosis in pigs slaughtered at Addis Ababa abattoir enterprise. The study aimed to determine the current prevalence status of cystic echinococcosis in pig and also to identify responsible risk factors for the prevalence of hydatidosis.

\section{MATERIALS AND METHODS}

\section{Study area}

The study was conducted at Addis Ababa Abattoirs Enterprise (AAAE). Addis Ababa, the capital of Ethiopia, is located at $9.03^{\circ}$ North latitude and $38.8^{\circ}$ East longitudes with an average altitude of 2400 meters above sea level. The city covers about 54,000 hectares of land with an average population of more than 3 million. It has an average temperature during winter $6^{\circ} \mathrm{C}$ minimum and $23^{\circ} \mathrm{C}$ maximum and during summer $10^{\circ} \mathrm{C}$ minimum and $24^{\circ} \mathrm{C}$ maximum with an annual temperature of $15.9^{\circ} \mathrm{C}$. It also receives an annual rainfall of $1089 \mathrm{~mm}$ with $60.1 \%$ annual relative humidity which ranges from 49\% in February to $82 \%$ in July 14 (National Meteorology Service Agency, 2007)

\section{Study animals}

The study population covers all swine brought for slaughter from various parts of the country to Addis Ababa abattoir enterprise. Main sources of pigs in this study were from Addis Ababa, Bishoftu, Akaki and Shogollie. All pigs belonging to both sex (male and female) were considered for the purpose of this study. During the study period age was determined using tooth eruption patterns (Xiaolin, 2004) and swine were classified as young if they were less eleven month and adult if they were greater or equal to eleven month age (Bewuket et al., 2014).

\section{Study design}

A cross-sectional study was conducted from January 2018 to April 2018 in Addis Ababa abattoir enterprise to determine the prevalence of hydatid cyst infection in slaughtered pigs by using gross post mortem inspection procedure of visceral organs including liver, lungs, kidneys, and spleen.

\section{Sampling method and sample size determination}

Simple random sampling method was used for sampling selection. In this abattoir ante mortem and post mortem, examination was done by giving a special identification code for diagnosed animals so that this code made the sampling system easy i.e. lottery method of selection was held daily by using animals code until the end of the required sample size. The required sample size of the study for pigs was determined by the formula given in Thrusfield (2005) with $95 \%$ of confidence interval and at $5 \%$ desired precision. By using this formula and expected prevalence of $17 \%$ in pigs slaughtered in the study area, then the required sample size becomes 217 . However, additional 34 samples were included as there was enough time to include extra samples which increases the precision of the study, and a total of 251 animals were examined for the presence of hydatid cysts in different organs like liver, lungs, kidneys and spleen for better conclusion.

$\mathrm{N}=\frac{\mathrm{Z}^{2} \mathrm{pq}}{\mathrm{d}^{2}}$; where $\mathrm{N}=$ number of animals to be sampled; $\mathrm{P}=$ expected prevalence, $\mathrm{P}=17 \%$; $d=$ desired absolute precision, $d=0.05$; the value of $Z$ at $95 \%$ confidence interval $=1.96$ 


\section{Prevalence study}

The study was directed from January 2018 to April 2018. Ante mortem and postmortem examinations were carried out on 251 pigs that were slaughtered at AAAE.

\section{Ante-Mortem examination}

Physical examinations of the study animals were performed prior to slaughter in order to record data on age, sex and body condition. Age was determined using tooth eruption patterns (Xiaolin, 2004) and classified as young if it was less than or equal to eleven month and adult if it is more than eleven month (Bewuket et al., 2014). Origins of the pigs were also recorded. In this abattoir ante mortem and post mortem, examination was done by giving a special identification code.

\section{Post-Mortem examination}

During the postmortem examination, a thorough visual inspection, palpation and systematic incision of each visceral organ particularly the lung, liver, kidney and spleen was carried out according to procedures recommended by FAO (1994). The total number of hydatid cysts in each affected organ was noted to calculate the load of burden on organ and study animals' level. All hydatid cysts that found in the organs were collected to conduct cyst count and cyst size measurement.

\section{Cyst number on infected organ}

The total number of hydatid cysts in each affected organ was noted to calculate the load of burden on organ and study animal level. All hydatid cysts that found in the organs were collected to conduct cyst count and cyst size measurement. After counting the cyst burden on the examined organ, it was then classified as less than three cysts and more than or equal to three cyst. This classification was based on the frequency of cyst number on examined organ during the study period.

\section{Cyst size measurement}

Individual cyst diameter were measured using a ruler and classified into three groups as small, medium and large if the diameter of the cyst were $<4 \mathrm{~cm}, 4-8 \mathrm{~cm}$ and $>8 \mathrm{~cm}$, respectively. This measurement was provided in the same way with the study of Schantz (1990). Approximately similar measurement was used with the study of Endrias et al. (2010) in which all cysts in an organ were counted, then subjected to systematic size measurement (diameter) using a ruler and classified as small cyst $(<3 \mathrm{~cm})$, medium cyst $(3-5 \mathrm{~cm})$ and large cyst $(>5 \mathrm{~cm})$.
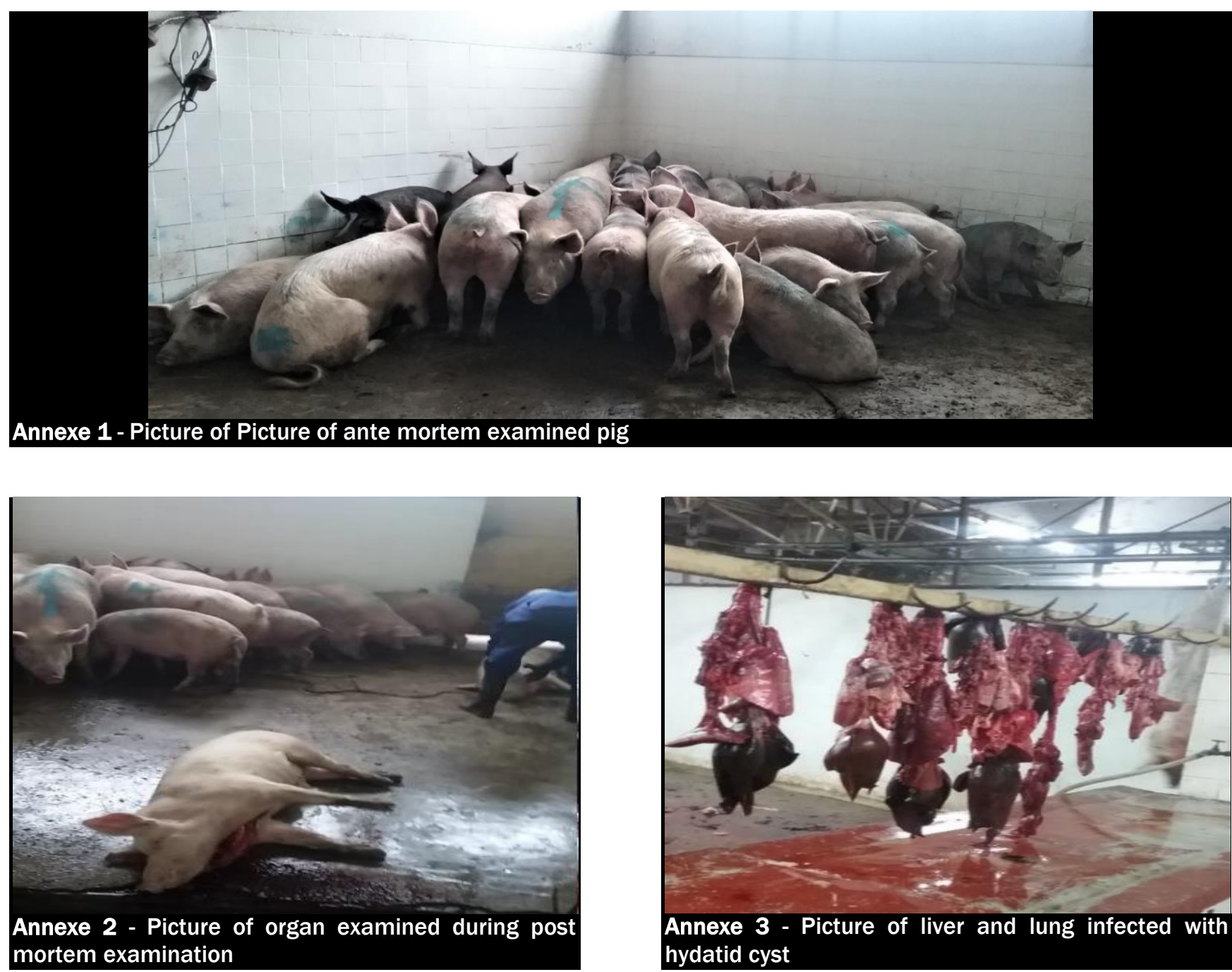


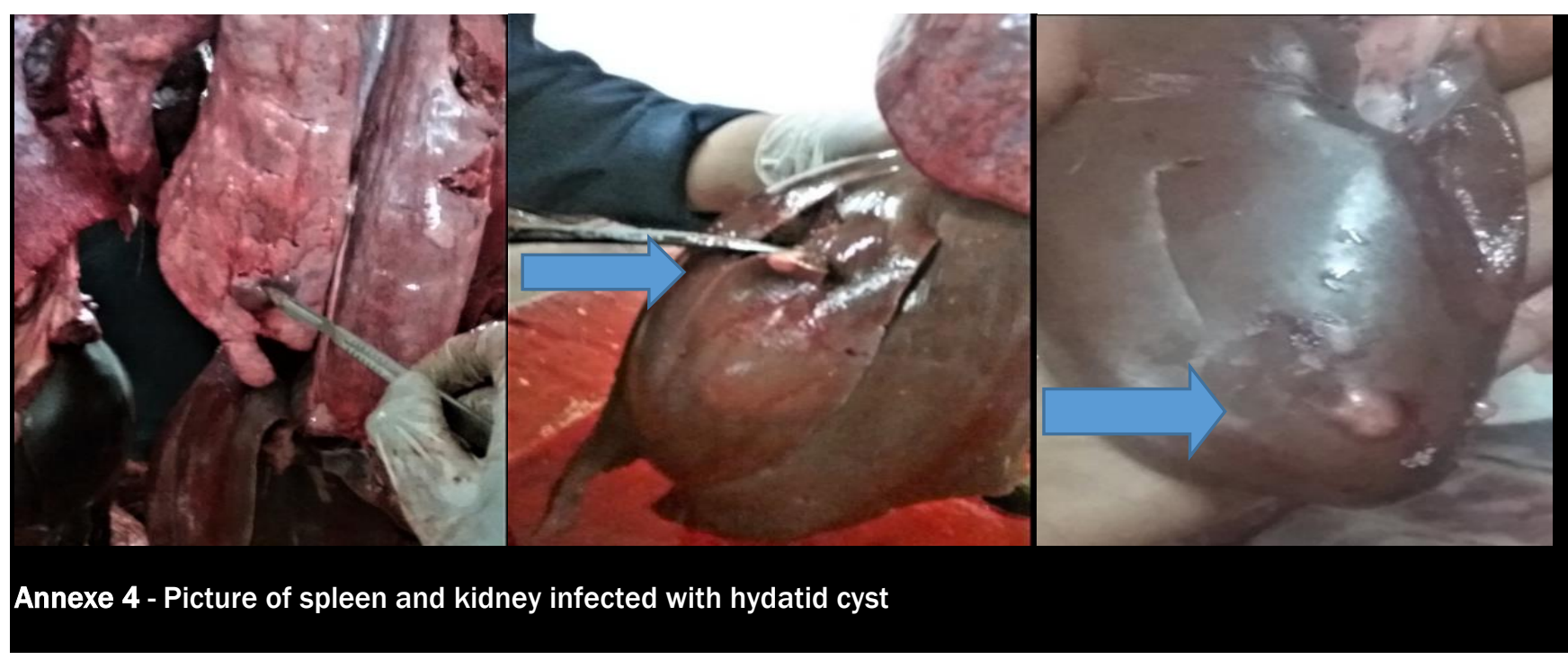

Data management and statistical analysis

The data collected was entered and scored in Microsoft excel worksheet. Before subjected to statistical analysis, the data was properly coded and thoroughly screened for errors. For analysis, STATA Microsoft software Version 14.1 was used. Descriptive statistical analysis such as frequencydistributions and cross-tabulations were used to summarize and present the data collected. Pearson chi square $\left(x^{2}\right)$ test was employed to assess the existence of association between prevalence of the hydatid cysts and different potential risk factors (age, sex, origin and body condition scores) considered. The total prevalence was calculated by dividing the number of hydatidosis positive animals by the total number of animals examined. For $\left(X^{2}\right)$ test, $p$ - value $<0.05$ were considered significant whereas $p$-value $>0.05$ considered non-significant.

\section{RESULTS AND DISCUSSION}

\section{The overall prevalence of hydatidosis}

Among 251 heads of pigs slaughtered at Addis Ababa abattoir enterprise, 9.96\% (25/251) were found infected with hydatid-cysts involving one or more different organs (Table 1). Rate of infection of hydatidosis in different age groups Young $12 \%(3 / 25)$ and Adult $88 \%(22 / 25)$ as well as body condition score with poor $40 \%(10 / 25)$, medium $32 \%(8 / 25)$ and good $28 \%$ (7/25) were statistically significant (Table 2). Rate of infection of hydatidosis in different sex, male56\% $(14 / 25)$ and female $44 \%(11 / 25)$ with prevalence within sex of $10.94 \%(14 / 128)$ and $8.94 \%(11 / 123)$ respectively and also origin, Addis Ababa, Akaki, Bishoftu, Shegollie with prevalence within origin of $6.66 \%(3 / 45), 12 \%(3 / 25), 8.05 \%$ $(12 / 149)$ and $21.87 \%(7 / 32)$ respectively were statistically not significant (Table 3$)$.

The postmortem examination revealed that the distribution of hydatid cysts involved lung, liver, spleen and kidney. Among 25 pigs harboring hydatid cyst, 16(64\%) of them had hydatid cyst infection only in a single organ whereas the remaining $9(36 \%)$ occurred in more than one organ with large proportion of pigs $9(36 \%)$ had cysts only on lung and liver combination. With regard to single organ liver was the most affected organ $8(32 \%)$ followed by lungs $5(20 \%)$, spleen $2(8 \%)$ and the least affected organ was the kidney which accounts only $1(4 \%)$ (Table 4$)$.

With regard to cyst size, on $\mathbf{3 4}$ affected organs only lungs have large cyst while the remaining affected organs have small and medium cyst size. Liver had the highest percentage (44.1\%) of small cyst. Spleen and kidney were the only organs that possess only small cyst size (Table 5). Except $4(11.8 \%)$ lungs which have more than or equal to three cyst number, all affected organs have distribution of less than three cysts number. Livers encompass highest percentage (50\%) of less than three cyst number. During the postmortem examination higher percentage $(\mathbf{8 8 . 2 \% )}$ of organs were infested with less than three cyst burden whereas only $\mathbf{1 1 . 8 \%}$ of cyst distribution on infected organ was with more than or equal to three cyst numbers (Table 6).

Table 1 - Total prevalence of affected pigs at Addis Ababa abattoir enterprise

\begin{tabular}{lccc} 
Examined swine & Frequency & Percent & Cumulative \\
\hline Affected pig & 25 & 9.96 & 9.96 \\
Non affected pig & 226 & 90.04 & 100.00 \\
Total & 251 & 100.00 & \\
\hline
\end{tabular}


Table 2 - Prevalence of hydatid cyst with regard to age group and body condition score

\begin{tabular}{lccccccc} 
Risk factor & $\begin{array}{c}\text { No. of } \\
\text { examined }\end{array}$ & $\begin{array}{c}\text { No. of } \\
\text { infected }\end{array}$ & Percentage & Prevalence & \multicolumn{1}{c}{$\begin{array}{c}\text { Total } \\
\text { Prevalence }\end{array}$} & $\begin{array}{c}\text { X2 } \\
\text { P<0.05 }\end{array}$ \\
\hline Young (<11 months) & 92 & 3 & $3 / 25(12 \%)$ & $3.26 \%$ & $1.19 \%$ & 7.2681 & - \\
Adult ( $\geq 11$ months & 159 & 22 & $22 / 25(88 \%)$ & $13.83 \%$ & $8.77 \%$ & - & 0.007 \\
Poor & 113 & 10 & $10 / 25(40 \%)$ & $8.85 \%$ & $3.99 \%$ & - & - \\
Medium & 113 & 8 & $8 / 25(32 \%)$ & $7.10 \%$ & $3.19 \%$ & 10.273 & 0.006 \\
Good & 25 & 7 & $7 / 25(28 \%)$ & $28 \%$ & $2.78 \%$ & - & - \\
Total & 251 & 25 & $100 \%$ & $9.96 \%$ & $9.96 \%$ & - & - \\
\hline
\end{tabular}

Table 3 - Prevalence of hydatid cyst with regard to origin and sex

\begin{tabular}{lcccccccc} 
Risk factor & No. of examined & No. of infected & Percentage & Prevalence & Total Prevalence & X2 & P>0.05 & - \\
\hline \multirow{2}{*}{ Origin } & Addis Ababa & 45 & 3 & $3 / 25(12 \%)$ & $6.66 \%$ & $1.20 \%$ & - \\
& Bishofu & 149 & 12 & $12 / 25(48 \%)$ & $8.05 \%$ & $4.78 \%$ & - \\
& Shegolie & 32 & 7 & $7 / 25(28 \%)$ & $21.87 \%$ & $2.79 \%$ & 6.3297 & 0.09 \\
\hline \multirow{2}{*}{ Sex } & Male & 128 & 14 & $14 / 25(56 \%)$ & $10.94 \%$ & $5.57 \%$ & - & \multirow{2}{*}{0.59} \\
& Female & 123 & 11 & $11 / 25(44 \%)$ & $8.94 \%$ & $4.38 \%$ & 0.2782 \\
\hline Total & 251 & 25 & $100 \%$ & $9.96 \%$ & $9.96 \%$ & - & - \\
\hline
\end{tabular}

Table 4 - Distribution of hydatid cyst in different organs

\begin{tabular}{lccc} 
Organ & $\begin{array}{c}\text { Number } \\
\text { infected }\end{array}$ & $\begin{array}{c}\text { Prevalence from } \\
\text { infected animal }\end{array}$ & $\begin{array}{c}\text { Prevalence from } \\
\text { total examined animal }\end{array}$ \\
\hline Lung \& Liver & 9 & $36 \%$ & $3.59 \%$ \\
Liver & 8 & $32 \%$ & $3.19 \%$ \\
Lungs & 5 & $20 \%$ & $1.99 \%$ \\
Spleen & 2 & $8 \%$ & $0.80 \%$ \\
Kidney & 1 & $4 \%$ & $0.40 \%$ \\
Total & 25 & $100 \%$ & $9.96 \%$ \\
\hline
\end{tabular}

Table 5 -Distribution of hydatidcysts in different organs with respect to size

\begin{tabular}{lcccc}
\hline \multirow{2}{*}{ Organ } & Small cyst & Medium cyst & Large cyst & Total \\
\cline { 2 - 5 } & Number with \% & Number with $\%$ & Number with \% & Number with \% \\
\hline Lungs & $5(14.7 \%)$ & $5(14.7 \%)$ & $4(11.8 \%)$ & $14(41.2 \%)$ \\
Liver & $15(44.1 \%)$ & $2(5.9)$ & 0 & $17(50 \%)$ \\
Spleen & $2(5.9 \%)$ & 0 & 0 & $2(5.9 \%)$ \\
Kidney & $1(2.9 \%)$ & 0 & 0 & $1(2.9 \%)$ \\
Total percent & $23(67.6 \%)$ & $7(20.6 \%)$ & $4(11.8 \%)$ & $34(100 \%)$ \\
\hline
\end{tabular}

\section{Table 6 - Distribution of hydatidcysts with regard to number of cysts}

\begin{tabular}{lccc}
\multirow{2}{*}{ Organ } & Less than three cyst & More than or equal to three cyst & Total \\
\cline { 2 - 4 } & Number with \% & Number with \% & Number with \% \\
\hline Lung & $10(29.4 \%)$ & $4(11.8 \%)$ & $14(41.2 \%)$ \\
Liver & $17(50 \%)$ & 0 & $17(50 \%)$ \\
Spleen & $2(5.9 \%)$ & 0 & $2(5.9 \%)$ \\
Kidney & $1(2.9 \%)$ & 0 & $1(2.9 \%)$ \\
Total & $30(88.2)$ & $4(11.8 \%)$ & $34(100 \%)$ \\
\hline
\end{tabular}

\section{DISCUSSION}

The present study found that the prevalence of hydatidosis in pig was $9.96 \%$, which can be regarded as high on what grounds? Provide a citation of a similar study that reported so. This high prevalence may generally relate to the presence of favorable factors for the transmission and maintenance of high level infection in the areas. This finding is in agreement with other prevalence studies in Africa; 19\% by Brahmi (1973), 5\% by Dada et al. (1979), 0.7\% by Larbaoni et al. (1980), $0.9 \%$ by Gathura et al. (1988), $4.6 \%$ by Rahman et al. (1992), and $16.9 \%$ by Bewuket et al. (2014), in Tunisia, Nigeria, Algeria, Kenya, Egypt, and Ethiopia respectively).

Unlike the results of the current study, Bewuket et al. (2014) recorded a higher prevalence of $16.9 \%$ (65/384) in Addis Ababa abattoir enterprise. This variation could have arisen due to the fact that Bewuket's data was gathered from different region of the country and his study period was higher than the current finding. This may be because in the past dogs were often kept close to intermediate hosts. On the contrary, such practices occur to a much lower degree these days due to enforcement of veterinary guideline. According to Garippa et al. (2004), variation in prevalence of hydatidosis from one area to other area could result from dissimilarities in animal husbandry systems like free grazing, uncorrected 
slaughter of animals, lack of proper removal of infectious carcass and the presence of more number of stray dog and their associations with animals. When compared to other countries in the world, varying prevalence of cystic echinococcosis have been reported in swine by several researchers. This finding (9.96\%) is lower than that of Lidetu and Hutchinson (2007) studies (31.1\%) in north Queensland. These researchers have done on the feral pigs. The result in this study might indicate that the prevalence of hydatidosis in pigs slaughtered at Addis Ababa abattoir enterprise has a low chance of getting the disease from dogs' compared to those of feral pigs. This might be because of dogs were highly contacting and the way they were feeding with feral pigs during hunting season; thus may contribute to the maintenance and raises of hydatid disease prevalence in feral pigs than the present study. Even though, degree of infection is less than that of feral pig there is the chance of getting the hydatiddiseases from dogs to different swine farms and abattoirs.

Livers and lungs were the most frequently infected visceral organs inspected. In the present study among pigs harboring hydatid cyst, 16(64\%) of them had hydatid cyst infection only in a single organ whereas the remaining $9(36 \%)$ occurred in more than one organ with large proportion of pigs $9(36 \%)$ had cysts only on lungs \& liver combination. With regard to single organ, liver was the most affected organ $8(32 \%)$ followed by lungs $5(20 \%)$, spleen $2(8 \%)$ and the least affected organ was the kidney which accounts only 1(4\%). This finding is in agreement with the literature that revealed hydatid cyst is most commonly found in liver and lung of ungulates (Hubbert et al., 1975). This could be reasonable by the fact that livers and lungs have the first great capillaries sites encountered by the migrating Echinococcus oncosphere (hexacanth embryo) which adopt the portal vein route and primarily negotiate hepatic and pulmonary filtering system sequentially before any other peripheral organ is involved (Kebede et al., 2009). During the study period spleen and kidney were the least affected organs in the examined pigs. This finding is in agreement with the study that indicated the liver and lungs are the most commonly affected organs with hydatid cyst. However development of hydatid cysts occurs occasionally in other organs and tissue when oncosphere escape in to the general systemic circulation (Urquhart et al., 1996).

In the current study, cysts were found more in liver $(6.78 \%)$ than lungs (5.58\%). The findings conform to those reported in a similar study by Bewuket et al. (2014) in which the liver was the highest infected organ than any other organs/tissues. The liver being the most commonly affected organ than any other organ might be due to the reflection of the route of parasite entry and seem to support the hypothesis of hepatic portal distribution of oncosphere leading firstly to liver infection (Schwabe, 1986). This also might be justified by the fact that pigs are slaughtered at adult age in Addis Ababa abattoir enterprise. During older ages, the liver capillaries were dilated and most oncosphere pass directly and used for hexacanth embryo to enter the lymphatic circulation at last that can be carried through the thoracic duct to the lungs (Bekele and Butako, 2010). This may decrease the prevalence of the occurrence of hydatid cysts in swine lungs, kidney and spleen during the study period.

During the study time single and multiple hydatid cyst distribution were recorded in different organs. Out of 34 infected organs, $\mathbf{1 4 . 7 \%}$ and $\mathbf{1 1 . 8 \%}$ of lungs had medium and large-sized cysts respectively while the liver (44.1\%) harbored higher number of small sized cysts. This finding is in agreement with the study of Larrieu et al. (2001) in which higher percentage of medium and large cysts in the lungs may be related with the softer consistency of the lung while the higher yield of calcified cysts in liver could be attributed to relatively higher reticulo endothelial cells and abundant connective tissue reaction of the organ. High proportion of small cysts on liver may be due to immunological response of the host which might preclude expansion of cyst size (Torgerson, 2002).

During the study period $30(88.2 \%)$ infected organs have less than three cyst count while only $4(11.8 \%)$ infected lungs have more than or equal to three cyst count. In this study liver have highest percentage (50\%) of less than three hydatid cyst count followed by lung $(29.4 \%)$, spleen $(5.9 \%)$ and kidney $(2.9 \%)$. Such variations in cyst abundance might be due to the spatial distribution and the infectivity of $E$. granulosuseggs and the susceptibility and defensive capabilities of the host that agree with the study of Macpherson et al. (1985).

The present finding revealed there was no statistical variation in the prevalence rates between the areas where the examined animals comes from (Bishoftu, Akaki, Shegolie and Addis Ababa). The reason for the absence of variation in the prevalence in those different places may be related with the presence of very similar environmental situation in all the four areas. However, other investigators Lidetu and Hutchinson, (2007) and Bewuket et al. (2014) found a variation in the prevalence's of swine hydatidosis for different areas having different environmental and climatic conditions, stocking rate and the abundance of infected definitive and other intermediate hosts. Other factors may be due to difference in feeding habits, social activity and attitude of peoples in difference region (Azlaf and Dakar, 2006) and difference in strains of $E$. granulosus that exist in different geographical location (Parijia, 2004).

Analysis of body condition of swine had significant association with the occurrence of the hydatid disease and swine with poor body condition were with higher prevalence of hydatidosis. The difference between bodies conditions score may be because swine with poor body conditions have low immunity to hydatidosis. This finding was in agreement with the result of Zelalem et al. (2012). And also Polydorous, 1981 reported moderate to severe infection of the parasite may cause retarded growth and weight loss. Bewuket et al. (2014) reported different results as the body condition had no significantly influence on the prevalence of hydatidosis.

There was significant variation $(P<0.05)$ in swine with different age groups where adult pigs were highly infected with the prevalence within age of $13.83 \%$ and young pig have $3.26 \%$ prevalence. This result is in consistence with 
Bewuket et al. $(2014)$ in which there was statistically significant variation $(P<0.05)$ in swine with different age groups where adult were highly infected with the prevalence of $23.55 \%$ and young pigs have $3.2 \%$ prevalence

\section{CONCLUSION}

In conclusion, the findings in this study showed that the prevalence of hydatidosis in pigs slaughtered at Addis Ababa abattoir enterprise was $9.96 \%$. Age and body condition were risk factors for hydatidosis infection. Among infected organs with hydatidosis, only lungs have large cyst size while the remaining affected organs have small and medium cyst size. Liver have highest percentage of small cyst. Spleen and kidney were the only organs that possess only small cyst size. Except lungs which have more than or equal to three cyst number, all affected organs have a distribution of less than three cysts number. In case of cyst number, higher percentage of organs was infested with less than three cysts. Livers encompass highest percentage of less than three cyst number. This result indicated that hydatidosis was a significant disease that disturbs swine. Based on the above conclusion the following recommendation is forwarded: 1) A serious farm to table swine health management should be advocated; 2) Rearing of swine by dividing in to their age and body condition should be advised for swine farm owners; 3) Educating of the society about hydatidosis life cycle and its consequence should be done. Further research should be conducted to study the potential sources of hydatidosis for effective prevention and analysis of its economic impact.

\section{DECLARATIONS}

\section{Authors' contributions}

MB conceived the study, coordinated the overall activity, and carried out the statistical analysis, drafted the manuscript and participated in the design of the study, and reviewed the manuscript. All authors read and approved the final manuscript. AY participated in drafting and reviewing the manuscript. EG conceived the study, coordinated the overall activity, and reviewed the manuscript and participated in drafting and reviewing the manuscript.

Availability of data and materials

Data will be made available up on request of the primary author.

Acknowledgment

The authors' heartfelt thanks University of Gondar, Research and Community service V/P office for financial supporting.

\section{REFERENCES}

Abdu S and Gashaw A (2010). Production system dynamism and parasitic interaction of swine in and around Holetta, Ethiopia, Ethiopian Veterinary Journal, $14(1): 71-81$

Ahmadi A and Meshkehkar M (2011). An abattoir-based study on the prevalence and economic losses due to cystic echinococcosis in slaughtered herbivores in Ahwaz, south-western Iran. Journal of helminthology, 85(1): 33-39.

Ali M, Khan H, Khan M, Khwanzada K, Ayub S and Rahman S (2008). Carnio orbital hydatidosis. Journal of Pediatric Neurology, 6(2): 125128.

Andualem Y (2007). Major causes of organs/ carcass condemnation in cattle slaughtered at Kombolcha ELFORA abattoir, South Wollo, Ethiopia. DVM thesis, Addis Ababa University, Faculty of Veterinary Medicine. Debrezeit, Ethiopia

Azlaf R and Dakar A (2006). Epidemiological study of cystic echinococcosis in Morocco. Veterinary parasitology, 2006. 137(1-2): p. 8393.Veterinary Parasitology, 137: 83-93.

Bekele J and Butako B (2010). Occurrence and financial loss assessment of cystic Echinococcosis or hydatidosis in cattle slaughtered at WolaitaSodo municipal abattoir, Southern Ethiopia. Tropical animal health and production, 43(1): p. $221-228$.

Berhe G (2009). Abattoir survey on cattle hydatidosis in Tigray region of Ethiopia. Tropical animal health and production. $41(7)$ : p. 1347.

Bewuket E, Asmare A and Mersha C (2014). Occurrence, Zoonosis, Risk Factors and Effect of Swine Hydatidosis in Pigs Slaughtered at Addis Ababa Municipal Abattoir (AAMA).

Brahmi C (1973). L'hydatidosehumaineetanimale en Tunisie. These Ecole Nationale Veterinaire de Lyon, Trion. Pp. 104.

Craig S, McManus P, Lightowlers W, Chabalgoity A, Garcia H, Gavidia M, Gilman, R.H., Gonzale, AE, Lorca M, Naquira C, Nieto A, Schantz PM (2007). Prevention and control of cystic echinococcosis. Lancet Infectious Diseases. 7 (6): 385-394.

Dada 0, Adegboye S and Mohammed N (1979). The epidemiology of Echinococcus infection in Kaduna State, Nigeria. The Veterinary Record, 104(14): 312-313.

Eckert J and Deplazes P (2004). Biological, epidemiological and clinical aspects of echinococcosis a zoonosis of increasing concern. Clinical microbiology reviews 17(1): 107-135.

Endrias Z, Yechale T and Assefa M (2010). Bovine hydatidosis in Ambo Municipality Abattoir, West Showa, Ethiopia. Ethiop. Veterinary Journal, 14 (1):p.1-14.

FAO/UNEP/WHO (1994). Guidelines for Echinococcosis/hydatidosis Surveillance, Prevention and Control. Rome: Food \& Agriculture Organization, No. 29, pp. 147.

Garippa G, Varcasia and Scala A (2004). Cystic echinococcosis in Italy from the 1950s to present. Parassitologia, 46(4): p. 387-391.

Gathura B, Kyule N and Gathuma M (1988). The Prevalence of Hydatid Disease in Pigs. Kenya: in press.

Gemmell A, Johnstone D and Oudemans G (1979). The effect of oxfendazole on Echinococcusgranulosus and Taeniahydatigena infections in dogs. Research in veterinary science, 26(3): 389-390. 
Irvin M (2003). Pig production science and technology. Leicestershire, United kingdom: Upfront publishing Ltd, pp. 3-10.

Kebede N, Mekonnen H, Wossene A and Tilahun G (2009). Hydatidosis of slaughtered cattle in WolaitaSodo Abattoir, Southern Ethiopia. Tropical Animal Health and Production, 41(4): 629-633.

Larbaoui D and Alloula R (1980). Hydatidosis in Algeria. Meditsinskaya Parazitologiya iournal of Parazitamya Bonlenzni, 49: 21-23.

Larrieu E, Costa T, Cantoni G, Alvarez R, Cavagion L, Labanchi L, Bigatti R, Araya D, Herrero E, Alvarez E, Mancini S and Cabrera P (2001). Ovine Echinococcus granulosustransmission dynamics in the province of Rio Negro, Argentina, 1980-1999. Veterinary Parasitology, 98(4): 263-272.

Lidetu D and Hutchinson G (2007). Prevalence, organ distribution and fertility of cystic echinococcosis in feral pigs in tropical North Queensland, Australia. Onderstepoort Journal of Veterinary Research. 74(1): 73-79.

National Meteorology Service Agency (2007). Addis Ababa, Ethiopia.

Nigatu K, Abebe M and Getachew T (2009). Hydatidosis of slaughtered animals in Bahir Dar Abattoir, North Western Ethiopia. Tropical Animal Health and Production, 41(1): 43-50.

Pam A, Daniel N, Bata I, Udokaninyene D, Hassan A (2013). An investigation of haemo and gastrointestinal parasites of pigs in some parts of Langtang, North Local Government Area of Plateau State. Journal of Veterinary Advances, 3(2): 79-86.

Parijia C (2004). Medical Parasitology, Protozoalogy and Helimenthology Text and Atlas.2 $2^{\text {nd }}$ ed. India: Chenna Medical book publisher, Pp. 221-229.

Rahman S, Sokkar M and Dahab S (1992). Comparative studies on hydatidosis in farm animals in Egypt. Deutschl and Tierartzlichi Wochenschrift, 99 (11): 438-440.

Schantz PM, 1990. Parasitic zoonosis in perspective. International Journal of Parasitology, 22: 165-166.

Serres H (2001). Manual of pig production in the tropics. $3^{\text {rd }}$ ed. Walling ford: Biddies press Ltd. rd United kingdom, pp. ix-106.

Sissays M, Uggla A and Waller J (2008). Prevalance and seasonal incidence of larval and adult cestode infections of sheep and goats in eastern Ethiopia. Tropical Animal Health and Production, 40 (6): 387-394.

Thrusfield M. (2018). Veterinary epidemiology, John Wiley \& Sons

Torgerson $\mathrm{P}$ (2002). Transmission dynamics of taeniid parasites in animal hosts. In Cestodezoononoses: echinoccosis and cysticercosis, an emergent and global problem. Craig, P. and Pawlowski, Z. ed. Amsterdam, the Netherlands: IOS press, pp. 221-235.

Torgerson R and Budke M (2003). Echinococcosis an international public health challenge. Research Veterinary Science, 74:p. $191-202$.

Urquhart M, Armour J, Duncan L, Dunn M and Jennings W (1996). Veterinary Parasitology. $2^{\text {nd }}$ ed. London, United Kingdom: Blackwell Science Ltd., Pp. 120-129.

Xiaolin A (2004). Pig husbandry strategies in a complex society, Central China. BIPPA, 2(24): p. 91-102.

Yetinayet G (2010). Prevalence and economic significance of Bovine hydatidosis in cattle slaughtered at Gondar ELFORA abattoir, North Gondar. DVM thesis, University of Gondar, Faculty of Veterinary Medicine, Gondar, Ethiopia.

Zelalem F, Tadele T, Zelalem N, Macial C and Kebede N (2012). Prevalence and character station of Hydatidosisi in animals slaughtered at Addis Ababa Abattoirs Enterprise, Ethiopia. Journal of parasitology and vector Biology, 4(1): 1-6.

Zhang W, Li J and McManus P (2003). Concepts in immunology and diagnosis of hydatid disease. Clinical Microbiology Reviews, 16(1): 1836. 